\title{
Climate-adjusted provenancing: a strategy for climate-resilient ecological restoration
}

\author{
Suzanne M. Prober ${ }^{1 * t}$, Margaret Byrne ${ }^{2 \dagger}$, Elizabeth H. McLean ${ }^{1,2}$, Dorothy A. Steane ${ }^{3,4}$, \\ Brad M. Potts ${ }^{3}$, Rene E. Vaillancourt ${ }^{3}$ and William D. Stock ${ }^{5}$ \\ ${ }^{1}$ Land and Water Flagship, Commonwealth Scientific and Industrial Research Organisation, Wembley, WA, Australia, \\ ${ }^{2}$ Science and Conservation Division, Department of Parks and Wildlife, Kensington, WA, Australia, ${ }^{3}$ Faculty of Science, \\ Engineering and Technology, School of Biological Sciences, University of Tasmania, Hobart, TAS, Australia, ${ }^{4}$ Faculty of \\ Science, Health, Education and Engineering, University of the Sunshine Coast, Sippy Downs, QLD, Australia, ${ }^{5}$ Centre for \\ Ecosystem Management, School of Natural Sciences, Edith Cowan University, Joondalup, WA, Australia
}

Keywords: climate adaptation, ecological restoration, genomics, plasticity, widespread species

\section{OPEN ACCESS}

Edited by:

Veerasamy Sejian,

Indian Council of Agricultural

Research, India

Reviewed by:

Konstantinos Ar. Kormas,

University of Thessaly, Greece

*Correspondence:

Suzanne M. Prober,

suzanne.prober@csiro.au

${ }^{\dagger}$ Joint first authors.

Specialty section:

This article was submitted to Interdisciplinary Climate Studies,

a section of the journal

Frontiers in Ecology and Evolution

Received: 24 April 2015

Accepted: 10 June 2015

Published: 23 June 2015

Citation:

Prober SM, Byrne M, McLean EH, Steane DA, Potts BM, Vaillancourt RE and Stock WD (2015)

Climate-adjusted provenancing: a strategy for climate-resilient ecological

restoration. Front. Ecol. Evol. 3:65.

doi: 10.3389/fevo.2015.00065

\section{Introduction}

Investments in ecological restoration are estimated at \$US 2 trillion per annum worldwide and are increasing rapidly (Cunningham, 2008; Williams et al., 2014). These investments are occurring in an environment of accelerated climate change that is projected to continue into the next century, yet they currently take little account of such change. This has significant implications for the longterm success of restoration plantings across millions of hectares, with germplasm used in current restoration efforts potentially poorly-adapted to future climates. New approaches that optimize the climate-resilience of these restoration efforts are thus essential (Breed et al., 2013; Williams et al., 2014; Havens et al., 2015).

A promising, but as yet untapped, opportunity for enhancing the climate-resilience of restoration investments rests in the exploitation of natural genetic variability of plant species. The capacity of plants to adapt to environmental change through plasticity, selection, or gene flow is only beginning to be explored (Nicotra et al., 2010; Hoffmann and Sgro, 2011; Aitken and Whitlock, 2013; Alberto et al., 2013). Informed strategies for sourcing germplasm that capitalize on inherent genetic diversity and adaptive capacity offer significant promise for improving the success of extensive plantings to restore landscapes that are eroded, salinized, desertified, highly fragmented or degraded through introduced competitors, herbivores, or diseases.

Here we describe a new strategy for sourcing germplasm for ecological restoration to promote adaptation in a changing climate. We argue that a "climate-adjusted" provenancing strategy (Figure 1A) should combine genetic diversity and adaptability, targeting projected climate change directions whilst allowing for uncertainty in such projections as well as unforeseen selective agents. We introduce climate-adjusted provenancing in the context of historical approaches to provenancing, and highlight emerging research to test this strategy.

\section{Provenancing Strategies}

Early ecological restoration typically focused on restoring ecological functions such as soil stability, using whatever plants were available to achieve these outcomes (including exotics, with many adverse outcomes). In recent decades, attention has turned to strategic sourcing of native germplasm for restoration plantings to achieve biodiversity conservation and other outcomes. Accordingly, an increasing awareness of the role of genetic provenance in plant performance has led to a strong theoretical and practical focus on maintaining local genetic-environmental relationships 
(McKay et al., 2005; Broadhurst et al., 2008). This strategy, typically known as "local" provenancing (Figure 1B), is based on evidence that in a static environment, local populations are best adapted to local conditions (Broadhurst et al., 2008).

More recently, arguments have been made to move away from a strict focus on local provenancing, toward the use of multiple or targeted provenancing strategies that address risks of inbreeding associated with collections from small and/or fragmented local populations, and begin to consider adaptation potential in relation to changing environments (Broadhurst et al., 2008; Breed et al., 2013). In particular, Broadhurst et al. (2008) proposed a shift to "composite" provenancing (Figure 1C), which aims to mimic natural patterns of gene flow by mixing seed from healthy local provenances combined with progressively smaller amounts of seed from more distant sites. Breed et al. (2013) further emphasized the importance of adaptability in their proposal for "admixture" provenancing (Figure 1D). This aims to build evolutionary resilience into plantings by mixing a wide variety of provenances from sources across a species range, without regard to the location of the planting site. They argued that such an approach is most appropriate when changes in conditions are expected but there are few data to indicate likely responses.

\section{Provenancing in a Changing Climate}

It is now a near-certainty that local climates are changing around the globe (IPCC, 2013). As the climate changes, local genetic adaptations will be increasingly weakened in situ, and a static view of genetic-environmental relationships will no longer be relevant. Instead, capturing advantages of local adaptations will need to account for spatial shifts in climate, and maximizing adaptation potential will be crucial (Aitken and Whitlock, 2013; Thomas et al., 2014).

Our climate-adjusted provenancing strategy thus proposes a targeted approach to enhancing the climate-resilience of restoration plantings, with seed sourcing biased toward the direction of predicted climatic change (Figure 1A), but not exclusive to it. Germplasm pools would incorporate a mix of genotypes from a climatic gradient, biased toward environments more likely to be encountered in the future, but would also include local genotypes. Other principles articulated by Broadhurst et al. (2008) regarding robust population health and diversity in source populations would still apply. This strategy aims to capitalize on potential for selection of pre-adapted genotypes and new gene combinations, while reducing risks associated with uncertainty in the projected magnitude and rate of future climate change, and maintaining genetic diversity for adaptation to other factors (Isaac-Renton et al., 2014).

We thus hypothesize that a climate-adjusted provenancing strategy offers the best compromise for capturing adaptive responses to climate in the face of uncertainty, by combining in situ plastic responses, adaptation, and selection occurring in the local gene pools, with genetic material that has evolved in environments more similar to projected futures of the restoration sites. Although future climate generally cannot be predicted with high certainty, the general trend of the change is often robustly
Direction of expected climate change at site e.g. site likely to increase in aridity

A Climate-adjusted provenancing

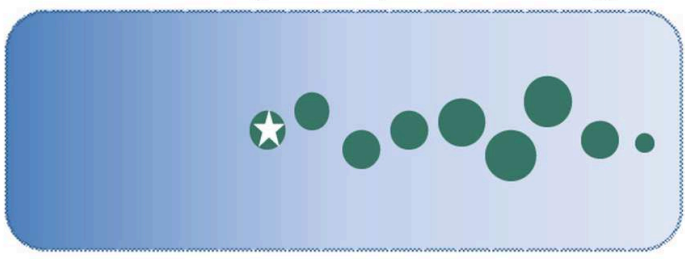

B Local provenancing

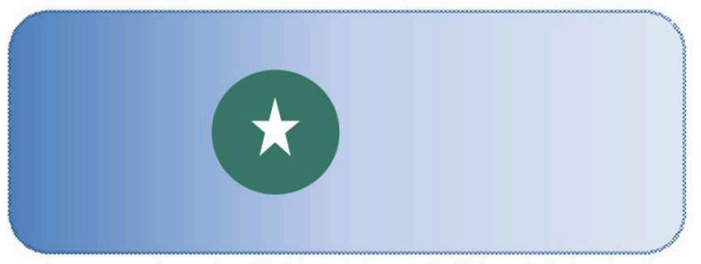

c Composite provenancing

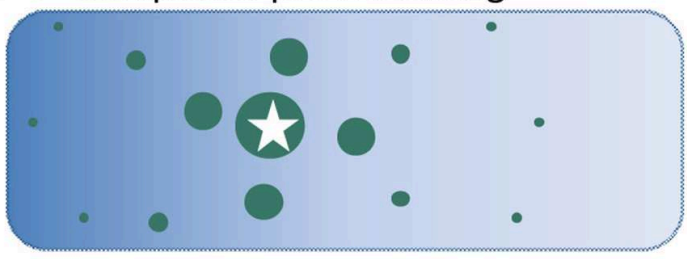

D Admixture provenancing

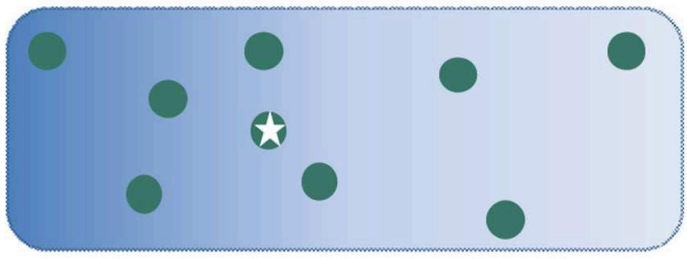

E Predictive provenancing

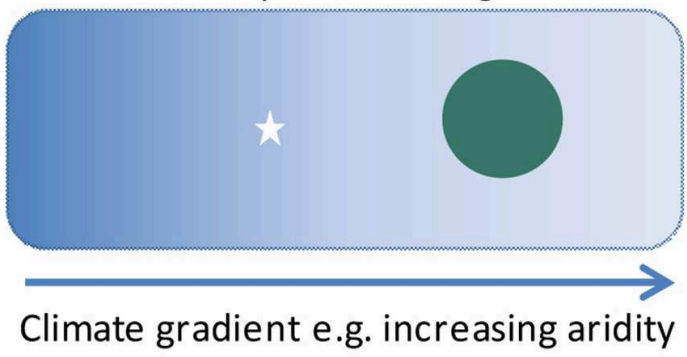

FIGURE 1 | Diagrammatic representations of provenancing strategies for revegetation, modified from Byrne et al. (2013). The star indicates the site to be revegetated, and the green circles represent native populations used as germplasm sources. The size of the circles indicates the relative quantities of germplasm included from each population for use at the revegetation site. In the case of the climate-adjusted provenancing the relative quantities of the germplasm from the various populations will depend upon factors such as genetic risks, and the rate and reliability of climate change projections. For simplicity we represent the major direction of climate change in a single dimension (e.g., aridity, to combine influences of increasing temperature and decreasing rainfall), but multiple dimensions could be considered as required. 
projected. For example, climates are projected to become drier and warmer in southern Australia (Kirono et al., 2011); climateadjusted provenancing would thus combine local germplasm with seed sourced from increasingly drier and warmer sites across the gradient, informed by a range of climate models. This strategy should be implemented within a genetic risk framework, that assesses potential benefits against risks of outbreeding depression to surrounding plant communities (Byrne et al., 2011; Weeks et al., 2011) and risks to dependent biota (Whitham et al., 2006). These considerations and the reliability, rate, and direction of climate change projections will influence the relative contribution of non-local provenances to the seed mix.

Climate-adjusted provenancing contrasts with "predictive" provenancing (Crowe and Parker, 2008; Wang et al., 2010; Sgrò et al., 2011, Figure 1E), a strategy that similarly targets adaptation to climate. The predictive provenancing approach proposes the use of naturally occurring genotypes that are experimentally determined to be adapted to projected conditions. This strategy has potential for high success should future conditions accurately match projections; however this is rarely certain in the case of climate change and does not allow for gradual directional shifts over time, leading to high risks in its application. Both climateadjusted provenancing and predictive provenancing are subsets of the more general concept of assisted gene flow for climate adaptation (Aitken and Whitlock, 2013), applied in a restoration context.

\section{Emerging Research Informing Climate-adjusted Provenancing}

Our formulation of the climate-adjusted provenancing strategy has drawn on accumulating observational evidence for functional variation in widespread species across climate gradients, and evidence for local adaptation (McKay et al., 2005; Broadhurst et al., 2008; Aitken and Whitlock, 2013; Savolainen et al., 2013). However, the circumstances where it is likely to be most effective are yet to be clearly characterized. Two emerging research areas need development toward a predictive framework that would directly inform the likely benefit of, and hence guide application of, provenancing approaches targeting climate-resilience: (1) characterizing patterns of and mechanisms underlying climaterelated adaptive variation using common garden, controlled environment, and genomic studies, and (2) assessing genetic risks associated with introduction of non-local germplasm.

Characterizing patterns and mechanisms associated with adaptive variation aims to determine which types of species are most likely to hold beneficial adaptive capacity in their genomes (e.g., widespread versus short-range endemic species; annuals vs. perennials), and how this links with different features conferring this adaptive capacity (e.g., variation in stomatal density or leaf thickness conferring drought tolerance). Regarding patterns of adaptive variation, whether adaptive capacity lies within or among populations is of particular interest (Aitken and Whitlock, 2013). If associated with inter-population genetic variation (i.e., local adaptation), a climate-adjusted provenancing strategy will be advantageous. If capacity to adapt already resides in local populations due to phenotypic plasticity within individuals
(Nicotra et al., 2010) or within-population genetic variation, then climate-adjusted provenancing may be unnecessary (Alberto et al., 2013).

There is a long history of common garden trials, particularly for tree species, that compare different plant provenances to evaluate linkages between plant traits, plant performance, and environment (Mátyás, 1996). In conjunction with controlled-environment studies, these are an important resource for understanding adaptive capacity, including identifying underlying mechanisms and helping to distinguish phenotypic plasticity from local genetic adaptations. For example, most studies of tree species from mid to low rainfall regions (including Betula, Pinus, Eucalyptus, and Quercus species) have shown evidence of local adaptation to climate or water stress, usually with evidence for phenotypic plasticity as well (McLean et al., 2014 and references therein). Extensive restoration efforts offer a practical environment in which well-designed common garden trials and associated direct tests of provenancing strategies could be embedded at minimal (although not negligible) cost.

Advances in genomic analysis, including genome-wide screening, whole-genome sequencing, and candidate gene analysis, have opened up exciting new opportunities for understanding the genomic basis of biological adaptation (Angeloni et al., 2012; Savolainen et al., 2013; Hoffmann et al., 2015). Early studies on plants have identified adaptive genetic variation along climate and moisture gradients using correlative approaches (Dillon et al., 2014; Steane et al., 2014), supporting the argument that assisted movement of germplasm across such gradients could enhance adaptation to future climates. Combining genomic data with common garden trials provides the opportunity to link genomic regions with functional traits, to help establish a more in depth understanding of adaptive capacity (Hoffmann et al., 2015). For example, combined ecophysiological and genomic studies in Eucalyptus tricarpa revealed that adaptation to aridity included differential plasticity in functional traits such as leaf thickness, and identified genomic regions that were putatively associated with adaptation to aridity (McLean et al., 2014; Steane et al., 2014).

Application of climate-adjusted provenancing also needs to be tested within the context of potential genetic risks, particularly outbreeding depression and disruption of local adaptation to non-climatic factors (see comprehensive discussion in Aitken and Whitlock, 2013). Using a modeling approach, Aitken and Whitlock concluded that minor outbreeding depression should not outweigh benefits of introduction of new alleles for climate adaptation unless populations are so small that immediate extinction is a risk. Potential maladaptations to other environmental factors, such as soil type or photoperiod, need to be evaluated within a systematic framework, and potential for cryptic variation should also be considered. For example, genome-wide scans revealed cryptic variation in the widespread Eucalyptus salubris that overrode potential climate signals relating to an aridity gradient, suggesting a case where uninformed application of climate-adjusted provenancing could be maladaptive (Steane et al., 2015).

Genomic approaches are likely to provide tools to accelerate the development of a framework to predict 
adaptive capacity and genetic risk across plant species based on taxonomic grouping, distributional patterns, and functional types (Aitken and Whitlock, 2013; Hoffmann et al., 2015). Such a predictive framework is urgently needed to directly inform the on-ground application of provenancing strategies.

\section{Conclusions}

Climate-adjusted provenancing aims to capture adaptive variation within species as a resource for facilitating climate adaptation and maintaining broader evolutionary flexibility in planted vegetation. A systematic understanding of inherent adaptive capacity within different plant functional, taxonomic, and distributional types could play a central role in decision

\section{References}

Aitken, S. N., and Whitlock, M. C. (2013). Assisted gene flow to facilitate local adaptation to climate change. Ann. Rev. Ecol. Evol. Syst. 44, 367-388. doi: 10.1146/annurev-ecolsys-110512-135747

Alberto, F. J., Aitken, S. N., Alia, R., Gonzalez-Martinez, S. C., Hänninen, H., Kremer, A., et al. (2013). Potential for evolutionary responses to climate change-evidence from tree populations. Glob. Change Biol. 19, 1645-1661. doi: $10.1111 / \mathrm{gcb} .12181$

Angeloni, F., Wagemaker, N., Vergeer, P., and Ouboug, J. (2012). Genomic toolboxes for conservation biologists. Evol. Appl. 5, 130-143. doi: 10.1111/j.1752-4571.2011.00217.x

Breed, M. F., Steed, M. G., Otewell, K. M., Gardner, M. G., and Lowe, A. J. (2013). Which provenance and where? Seed sourcing strategies for revegetation in a changing environment. Conserv. Genet. 14, 1-10. doi: 10.1007/s10592-0120425-z

Broadhurst, L. M., Lowe, A. J., Coates, D. J., Cunningham, S. A., McDonald, M., Vesk, P. A., et al. (2008). Seed supply for broadscale restoration: maximizing evolutionary potential. Evol. Appl. 1, 587-597. doi: 10.1111/j.17524571.2008.00045.x

Byrne, M., Prober, S. M., McLean, E., Steane, D., Stock, W., Potts, B., et al. (2013). Adaptation to Climate in Widespread Eucalypt Species. Gold Coast, QLD: National Climate Change Adaptation Research Facility.

Byrne, M., Stone, L., and Millar, M. A. (2011). Assessing genetic risk in revegetation. J. Appl. Ecol. 48, 1365-1373 doi: 10.1111/j.13652664.2011.02045.x

Crowe, K. A., and Parker, W. H. (2008). Using portfolio theory to guide reforestation and restoration under climate change scenarios. Clim. Change 89, 355-370. doi: 10.1007/s10584-007-9373-x

Cunningham, S. (2008). ReWealth!: Stake your Claim in the \$2 Trillion Redevelopment Trend that's Renewing the World. New York, NY: McGraw Hill.

Dillon, S., McEvoy, R., Baldwin, D. S., Rees, G. N., Parsons, Y., and Southerton, S. (2014). Characterisation of adaptive genetic diversity in environmentally contrasted populations of Eucalyptus camaldulensis Dehnh. (River Red Gum). PLoS ONE 9:e103515. doi: 10.1371/journal.pone.0103515

Havens, K., Vitt, P., Still, S., Kramer, A. T., Fant, J. B., and Schatz, K. (2015). Seed sourcing for restoration in an era of climate change. Nat. Area. J. 35, 122-133. doi: $10.3375 / 043.035 .0116$

Hoffmann, A. A., and Sgro, C. M. (2011). Climate change and evolutionary adaptation. Nature 470, 479-485. doi: 10.1038/nature09670

Hoffmann, A., Griffin, P., Dillon, S., Catullo, R., Rane, R., Byrne, M., et al. (2015). A framework for incorporating evolutionary genomics into biodiversity conservation and management. Clim. Change Responses 2, 1-23 doi: 10.1186/s40665-014-0009-x

IPCC. (2013). "Summary for policymakers," in Climate Change 2013: The Physical Science Basis, Contribution of Working Group I to the Fifth Assessment Report of frameworks toward application of such provenancing strategies for climate-resilient restoration.

\section{Author Contributions}

All authors contributed to the development of ideas, SP and MB wrote the manuscript with input from all authors.

\section{Acknowledgments}

This work was supported by the National Climate Change Adaptation Research Facility (Australia, Project number TB11 03), the Great Western Woodlands Supersite, part of Australia's Terrestrial Ecosystem Research Network and the Australian Research Council (LP120200380).

the Intergovernmental Panel on Climate Change, eds T. F. Stocker, D. Qin, G. K. Plattner, M. Tignor, S. K. Allen, J. Boschung, et al. (Cambridge: Cambridge University Press), 29.

Isaac-Renton, M. G., Roberts, D. R., Hamann, A., and Spiecker, H. (2014). Douglas-fir plantations in Europe: a retrospective test of assisted migration to address climate change. Glob. Change Biol. 20, 2607-2617. doi: 10.1111/gcb. 12604

Kirono, D. G. C., Kent, D. M., Hennessy, K. J., and Mpelasoka, F. (2011). Characteristics of Australian droughts under enhanced greenhouse conditions: results from 14 global climate models. J. Arid Environ. 75, 566-575. doi: 10.1016/j.jaridenv.2010.12.012

Mátyás, C. (1996). Climatic adaptation of trees: rediscovering provenance tests. Euphytica 92, 45-54. doi: 10.1007/BF00022827

McKay, J. K., Christian, C. E., Harrison, S., and Rice, K. J. (2005). 'How local is local?' - a review of practical and conceptual issues in the genetics of restoration. Rest. Ecol. 13, 432-440. doi: 10.1111/j.1526-100X.2005.0 0058.x

McLean, E. H., Steane, D. A., Prober, S. M., Stock, W. D., Potts, B. M., Vaillancourt, R. E., et al. (2014). Plasticity of functional traits varies clinally along a rainfall gradient in Eucalyptus tricarpa. Plant Cell Environ. 20, 987-1001 doi: $10.1111 /$ pce. 12251

Nicotra, A. B., Atkin, O. K., Bonser, S. P., Davidson, A. M., Finnegan, E. J., Mathesius, U., et al. (2010). Plant phenotypic plasticity in a changing climate. Trends Plant Sci. 15, 684-692. doi: 10.1016/j.tplants.2010. 09.008

Savolainen, O., Lascoux, M., and Merilä, J. (2013). Ecological genomics of local adaptation. Nat. Rev. Genet. 14, 807-820. doi: 10.1038/ nrg3522

Sgrò, C. M., Lowe, A. J., and Hoffmann, A. A. (2011). Building evolutionary resilience for conserving biodiversity under climate change. Evol. Appl. 4, 326-337. doi: 10.1111/j.1752-4571.2010.00157.x

Steane, D. A., Potts, B. M., McLean, E., Collins, L., Prober, S. M., Stock, W D., et al. (2015). Genome wide scans reveal cryptic population structure in a dry-adapted eucalypt. Tree Genet. Genomes 11:33. doi: 10.1007/s11295-01 5-0864-z

Steane, D. A., Potts, B. M., McLean, E., Prober, S. M., Stock, W. D., Vaillancourt, R. E., et al. (2014). Genome-wide scans detect adaptation to aridity in a widespread forest tree species. Mol. Ecol. 23, 2500-2513. doi: 10.1111/mec. 12751

Thomas, E., Jalonen, R., Loo, J., Boshier, D., Gallo, L., Cavers, S., et al. (2014). Genetic considerations in ecosystem restoration using native tree species. Forest Ecol. Manag. 333, 66-75. doi: 10.1016/j.foreco.2014. 07.015

Wang, T., O’Neill, G. A., and Aitken, S. N. (2010). Integrating environmental and genetic effects to predict responses of tree populations to climate. Ecol. Appl. 20, 153-163. doi: 10.1890/08-2257.1 
Weeks, A. R., Sgrò, C. M., Young, A. G., Frankham, R., Mitchell, N. J., Miller, K. A., et al. (2011). Assessing the benefits and risks of translocations in changing environments: a genetic perspective. Evol. Appl. 4, 709-725. doi: 10.1111/j.1752-4571.2011.00192.x

Whitham, T. G., Bailey, J. K., Schweitzer, J. A., Shuster, S. M., Bangert, R. K., Leroy, C. J., et al. (2006). A framework for community and ecosystem genetics: from genes to ecosystems. Nat. Rev. Genet. 7, 510-523. doi: 10.1038/ $\operatorname{nrg} 1877$

Williams, A. V., Nevill, P., and Krauss, S. L. (2014). Next generation restoration genetics: applications and opportunities. Trends Plant Sci. 19, 529-537. doi: 10.1016/j.tplants.2014.03.011
Conflict of Interest Statement: The authors declare that the research was conducted in the absence of any commercial or financial relationships that could be construed as a potential conflict of interest.

Copyright ๑ 2015 Prober, Byrne, McLean, Steane, Potts, Vaillancourt and Stock. This is an open-access article distributed under the terms of the Creative Commons Attribution License (CC BY). The use, distribution or reproduction in other forums is permitted, provided the original author(s) or licensor are credited and that the original publication in this journal is cited, in accordance with accepted academic practice. No use, distribution or reproduction is permitted which does not comply with these terms. 